\title{
Innovation Leaders: An Interview with Bushra Anjum
}

\author{
Learning to be a generalist is valuable to your career. \\ by Peter Denning
}

\section{Editor's Introduction}

Dr. Bushra Anjum is a senior editor for ACM's web-based magazine Ubiquity. Her research background is in performance evaluation and queuing theory. She is also a trained data scientist, having worked extensively with predictive analytics. Anjum, a Fulbright Scholar, has previously held academic positions in the U.S. and Pakistan, and is a keen enthusiast of promoting diversity in the STEM fields. She is a mentor at Rewriting the Code, GlobalTechWomen, ReigningIt, Empowering Leadership Alliance, LeanIn.org, Computing Beyond the Double Bind's mentoring network, and others. Dr. Anjum can be contacted via Twitter@DrBushraAnjum. 


\title{
Innovation Leaders: An Interview with Bushra Anjum
}

\author{
Learning to be a generalist is valuable to your career.
}

\section{by Peter Denning}

\section{Ubiquity: Where are you directing your professional leadership activities?}

Bushra Anjum: The computing revolution is fostering a fusion of technologies that is quickly blurring the lines between real and virtual, physical and digital. Today's technical workforce is facing a world of accelerating change, many surprises, and a constant threat of rapid obsolescence. I have witnessed first-hand young people, aiming to become engineers, struggling with these threats. I have taught internationally, both in Pakistan and in the United States, and have been actively mentoring engineering students, both in person and as a virtual mentor at various forums. I want to help these people set themselves up for successful and influential careers in an industry where expertise seems to have a half-life less than six years.

I have concluded from my experience that the most critical training for young engineers is to understand and grow the mindset of a generalist. Rather than being tied to, or specialized in, a particular area, technology, language, or framework, a generalist engineer focuses on gaining a basic working knowledge of multiple domains, principles, and techniques, and goes deep when there is a professional need, or personal interest, in doing so. Further, these engineering generalists know how to learn, i.e., when it is time to dig deeper in a particular area for a given project, they know how to bring themselves up to speed quickly by finding the right resources, experimentation and, most importantly, engaging with people who have worked on similar and related problems in various domains.

Ubiquity: A lot of our computer science and engineering education focuses on developing deep expertise in some aspect of computing, such as artificial intelligence or cyber security. What has changed that puts this focus into jeopardy? 
BA: It is essential to understand that until recent past, domain experts were the go-to resource when one needed a deeper understanding of a problem in a specific area. These individuals devoted their entire careers to one particular domain, working in, retaining, and growing its knowledge base. Things are different in the digital tech industry, especially today. The concept of a domain is becoming increasingly fluid as technology is progressing at an accelerating speed. Furthermore, today knowledge and people are independently evolving, loosely coupled entities. A particular domain of knowledge is a living and growing entity with many sources contributing to it daily such as books, papers, opinions, forums, and experiences of people working on relevant projects. If one needs a deeper understanding of a particular area, one does not need to find a domain expert; instead, one needs to know how to engage with this thriving body of knowledge. This engagement may mean studying, experimentation, asking questions at virtual forums, interviewing people in person, and gathering wisdom from others who have worked on similar or related problems. As a result of this hands-on approach, as one finds a solution that meets one's requirement, one also adds learning to this pool of knowledge before moving on to the next area, the next challenge.

It may sound counterintuitive, but it was my Ph.D. that helped me become a generalist. I learned how to learn, and I learned how to contribute and move on. Graduate school builds in the maturity of letting yourself go, i.e., have the discipline to learn and explore new fields, and reigning yourself in, i.e., not allowing your pride or past successes tie you to a particular area.

\section{Ubiquity: How do you advise students to proceed in this world?}

BA: Students aiming at being successful engineers in the tech field should learn to be personable, to learn and adapt quickly, to find insights from across disciplinary boundaries, to contribute, and to move on to the next challenge. In my opinion, in our age, such engineering generalists are in high demand and will rarely be out of a job. As a visiting professor and an active mentor, $I$ invest heavily in training and advising students to become part of such a "future- proof" workforce.

Specialization has its place. People may choose to continue working in a particular area because of personal interest, or because their job may require them to have a set focus. However, people who choose to do this need to maintain constant vigilance that their specialty continues to be valuable. Otherwise, they can be lulled into the false belief their expertise will keep them employed. Specialization is also an effective marketing technique. When you apply for a job, you should present yourself as a person with the right expertise and skills by editing your 
portfolio to match the job requirements. However, when it comes to actual on-the-job performance, complex problem solving, critical thinking, cognitive flexibility, ability to communicate, and active learning will move you forward. Interestingly, these are the top skills for 2020 for the information and communication technology industry as reported by The Future of Jobs Report 2018, published by the World Economic Forum.

It is nevertheless important to acknowledge that our current common sense inclines us to skepticism about being a generalist; popular idioms like "jack of all trades, master of none" make it seem that generalists are dilettantes. It is time for a new common sense to break that taboo. Our industry is increasingly partial towards generalists. Knowing several areas, and knowing how to dig deeper when required, has proven to be far more valuable than achieving expertise in a single one. A successful engineer of the future is a generalist with a trained interdisciplinary and cross-functional mindset and whose training is augmented by the key human values of creativity, empathy, and flexibility. If you are inclined to gain mastery, master the mindset of an engineering generalist. Contact me and I'll help you do that.

\section{About the Author}

Peter Denning is past president of ACM (1980-82) and is Distinguished Professor, Chair of the Computer Science Department, and Director of the Cebrowski Institute at the Naval Postgraduate School in Monterey, California. He is also the Editor in Chief of Ubiquity Magazine.

DOI: $10.1145 / 3291937$ 